\title{
ESTUDIO DE LAS DIATOMITAS DE ICA COMO MATERIA PRIMA EN LA FABRICACIÓN DE ÁRIDOS ARTIFICIALES DE ARCILLA PARA SU USO COMO AGREGADOS LIGEROS EN MEZCLAS DE HORMIGÓN DISEÑADOS EN BASE A LAS EXIGENCIAS DE LA NTP Y ASTM
}

Jamie Galvez-Alvarado, Carlos Barzola-Gastelú, Rosmery Gómez-Minaya, Ana Torre-Carrillo

\section{RESUMEN}

El presente estudio se desarrolló con el fin de reducir el peso unitario del hormigón mediante el empleo de agregado liviano artificial, como reemplazo de los agregados convencionales (piedra y arena de origen natural). La investigación examina el material de diatomita sinterizada a temperaturas superiores a los $1000{ }^{\circ} \mathrm{C}$ como propuesta de agregado liviano. Este material presenta un peso unitario aproximado de $60 \%$ del correspondiente a los agregados convencionales. La diatomita que conforma la materia prima para la fabricación de este agregado fue estudiada bajo los mismos estándares de calidad utilizados en agregados convencionales, en cumplimiento de las normas ASTM y NTP. Los resultados obtenidos muestran a los agregados de diatomita cocida con resistencias a compresión promedio de $45 \mathrm{MPa}$, pesos unitarios de $970 \mathrm{~kg} / \mathrm{m}^{3}$ para agregado grueso y $1170 \mathrm{~kg} / \mathrm{m}^{3}$ para agregado fino, además de resistencias químicas acorde a las exigencias de la norma ASTM C1260 - 14. En los ensayos de hormigón con agregado de diatomita, se encontraron valores de peso unitario alrededor de $1785 \mathrm{~kg} / \mathrm{m}^{3}$, donde se muestra un comportamiento a compresión adecuado para resistencias de diseño f'c de $21 \mathrm{MPa}$.

Palabras Clave: Diatomita, Agregado Artificial, Sinterización, Materiales Refractarios, Quemado, Hormigón, Ligero.

DOI: 10.23881/idupbo.020.1-9i 